\title{
Energy Storage with Inclusion of Power Stability Improvement with Advanced Controls Based on VLSI
}

\author{
B. Pullarao, S. Srinivasan
}

\begin{abstract}
Multi rate strategy is fundamental for systems with different data and yield taking a gander at rates. Late advances in negligible figuring and correspondence applications deals low power and rapid VLSI DSP structures. This Paper presents Multi rate modules used for binding to offer sign overseeing in remote correspondence structure. Distinctive arranging made for the structure of low multifaceted nature, bit parallel Multiple Constant Multiplications improvement which principles the unusualness of DSP systems. In any case, basic hindrances of present approaches are either outrageously extravagant or not profitable enough. On the other hand, MCM and digit-consecutive snake offer elective low multifaceted nature plans, since digit-dynamic structure consolidate less space and are free of the data word length. Distinctive Constant Multiplications is capable way to deal with oversee decrease the proportion of enlargement and subtraction in poly stage channel execution. This Multi rate structure believing is purposeful and real to various issues. In this paper, thought has given to the MCM and digit dynamic structure with moving and including technique that offers elective low multifaceted nature in exercises. This paper what's more pivoted around Multi rate Signal Processing Modules using Voltage and Technology scaling. Lessening of intensity use is giant for VLSI system and moreover it ends up one of the most fundamental game-plan parameter.
\end{abstract}

Keywords: VLSI, DSP, TSMC, multiply constant multiplication (MCM)

\section{INTRODUCTION}

Power is a noteworthy utility in the moved society, with relationship including creating creation to get-together, from electronic correspondence [2] to media and web, and from accommodating plan to living conditions. Electric monstrosity use has reliably climbed since its mechanical introduction in the second half of the nineteenth century. Genuinely the world's inflexible electrical imperativeness creation in 2009 was around 20,000 TWh, which is in regard to a passed on (and ate up) force of around 2.3 TW everything considered. This level of customary power usage is cleaned by a mix of power age stations [50], including warmth engines filled by substance eating up or nuclear secluding, interesting vitality of spilling water and wind, sun based photo voltaics and geothermal frameworks. Non-plausible power sources (coal, gas, and oil in particular sales) address $67 \%$, supportable power source (generally hydroelectric, wind, sun orchestrated, and biomass) for $16 \%$, nuclear power for $13 \%$,

Revised Manuscript Received on September 22, 2019.

B.Pullarao, Research Scholar, Department of Electronics \& Communication Engineering, Saveetha School of Engineering, Chennai.

E-mail: bandipullarao89@gmailcom

Dr.S.Srinivasan, Professor \& HOD, Department of Biomedical Engineering, Saveetha School of Engineering, Chennai

E-mail: srinivasan.me03@gmail.com and various hotspots for $3 \%$ of all electrical centrality made the world over. Surges of dangerous substances and ozone exhausting substances out of oil reinforcement based power age are in charge of a colossal piece of world ozone hurting substance releases. In any case, Solar PV age is advertized as consistently welcoming [9], age of PV cells utilizes a great deal of water regardless of releasing hazardous created advancements, for instance, phosphorus and arsenic. Reliable supply of electric imperativeness is additionally an essential issue. Power outage is seen as an open emergency as people take the openness of unremitting force supply for permitted. Electrical centrality use in a system changes after some time in light of changes in the power necessities of weight contraptions in like manner as the customers' practices. Weight following power plants (for example, non-supportable power source power plants [28] [7] ) are proposed to administer rapid changes in power demands on the power network. In addition, the system requires [18] a particular level of working store, which is incorporated turning and non-turning spares, to keep up a fundamental decent ways from power blackouts and brownouts. Turning store shows the on-line extra creation limit [10] to deal with the pinnacle power demand that can deliver for a compact time task.

Non-turning save, clearly, derives the isolated extra creation cutoff that can be turned on and related with the power sort out after a short deferral. Both the turning and non-turning [29] stores require extra capital endeavor by the association relationship for their age office game-plan and action. Hold control age is ordinarily more ludicrous than the essential action on the power structure [14]. A couple of countries have starting late negligible additional edge during the zenith hours, which arrangements the power free market action match and offers move to risky working store guardian banding. This can benefit by outside assistance by structure extra power plants [49]. Regardless, improvement of new power plants requires enormous capital endeavor and has social and characteristic costs.

\section{LITERATURE REVIEW}

P. R. Abel, Y.- M. Lin, H. Celio, A. Heller, and C. B. Mullins (2012) Integration of STATCOM with importance collecting contraptions expect a focal work in improving the power structure movement and control.

Huge research has been done around there for sensible declaration of extraordinary states of the association. This paper, regardless, pays express monstrosity to the show improvement for the vagrants as is reachable by STATCOM

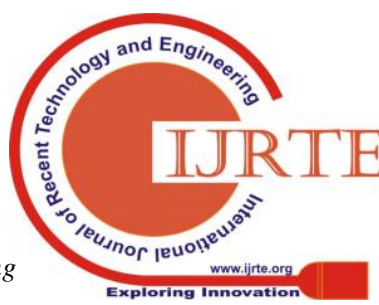


with battery-filled limit structures. Utilization of STATCOM with most distant point concerning sporadic reasonable power sources, for instance, wind control age is likewise inspected in the paper. Close to the beginning of this paper, a general review of the STATCOM and imperativeness social event structures are clarified. A short chart of the upsides of using STATCOM identified with centrality securing systems in achieving power structure security is showed up. In the second bit of the paper, a commonplace transient healthiness model of a STATCOM is showed up. The fragments of bona fide and open power responses of the dealt with structure to vagrants is considered. The assessment is anticipated showing that the mix of STATCOM and battery importance amassing on a very basic level improves the introduction of the structure. The last results show that the STATCOM open power/voltage control helps in transient adequacy update.

H. Akagi and H. Sato (2002) The VLSI Circuits and Systems Letter is aide with the Technical Committee on VLSI (TCVLSI) under the IEEE Computer Society. It might want to report late advances in VLSI improvement, preparing and openings and, thusly, build up the assessment and heading practices in the zone. The letter covers the strategy points of view for forefront VLSI circuit and structures, including modernized circuits and systems, fundamental and radio-repeat circuits, additionally as mixed sign circuits and structures. It was appropriated on different occasions each year. Starting from this year, we will pass on three issues for reliably to fulfill the phenomenal need from our area. TCVLSI pivots around joining the structure, PC helped plan, creation, application, and business parts of VLSI while wrapping both hardware and programming. It underpins various premium get-togethers and workshops, including, regardless not obliged to, ASAP, ASYNC, ISVLSI, IWLS, SLIP, and ARITH. Rising evaluation focuses and state-ofthe-craftsmanship impels on VLSI circuits and structures are addressed at these events ceaselessly.

F. Altaf, L. Johannesson, and B. Egardt (2012) The Internet of Things (IoT) is making as an attracting setting including physical perceptions, automated exchanges, social affiliations and even mental absolutely considering an advanced physical-social-thinking hyperspace. In this stand-out circumstance, significance the board with the explanations behind essentialness saving and high adequacy is a tricky issue. In this work, a shrewd solicitation model is set up in reference to the IoT layers (i.e., sensor-actuator layer, orchestrate layer, and application layer), and IoT essentialness the board is tended to from the perspectives of free market action to achieve green attestation, correspondence, and enrolling. A clever home circumstance is showed up as a significant appraisal incorporating the key attracting headways with supply-side, demand side, and supply-demand balance contemplations, and open issues in the field of IoT imperativeness the specialists are also discussed.

\section{OBJECTIVES}

To study Integrating STATCOM and Battery Energy Storage System for Power System Transient Stability: A Review and Application
To Implementation of FPGA Based Hybrid Power Generator for PV and Wind Grid Applications

To study Supply and Demand Oriented Energy Management in the Internet of Things

To structure VLSI Circuits and Systems Letter

To study Computer-Aided Design and Optimization of Hybrid Energy Storage Systems

\section{PROBLEM STATEMENT}

Power is the course to the best working of present day human culture. Constantly extending force use offers move to diligent rules and crucial endeavors to improve the criticalness capability in a wide degree of human headway from get-together to business, from transportation to front line correspondence, from beguilement to PCs and strong contraptions. A fundamental improvement for reducing centrality use is the ability to store any excess electrical criticalness for wide stretches of time and ably recuperate the set away essentialness. The approach and the administrators of electrical significance accumulating structures is the motivation behind mixing of the present paper, which starts off by objecting and looking sorts of electrical imperativeness securing sections concerning various estimations of enthusiasm reaching out from power and centrality thickness to yield power rating and from self-spillage rate to cost per unit of set away essentialness, and from life cycle of the limit part to the limit of the charge/discharge cycle. Next the paper considers undeniable imperativeness securing systems while instigating the requirement for a mutt significance putting away structure included heterogeneous sorts of hugeness social affair bits made in a dynamic manner so as to veil the inadequacies of each purpose of control part while prodding their qualities. The paper continues with a base need explanation of key challenges that one faces when dealing with the perfect structure and runtime the experts of a cross breed criticalness conglomerating structure concentrating on some specific application condition; for example, framework scale essentialness the administrators, nuclear family zenith power shaving, adaptable stage power saving, and that is just a gander at something greater. An investigation of some present responses for these issues is furthermore included.

\section{THEORY ON ADVANCED CONTROLLERS}

In automated VLSI framework course of action space, essential idea has been given to the structure of world class microchips. Notwithstanding, as of late, the energy for power precarious plans has developed fundamentally. This immense interest has generally been a consequence of the rapid improvement of battery-worked worthwhile applications, for example, individual moved associates, PDAs, restorative applications, remote recipients, and other versatile explicit contraptions. Further, in perspective on the forceful scaling of transistor sizes for world class applications, not exclusively does subthreshold spillage current enlargement exponentially, yet likewise passage spillage and switch uneven source-substrate and channel substrate intersection focuses band-to-band burrowing (BTBT) streams increment all around. The burrowing streams are severely intended to the handiness of the gadgets.

Appreciated approaches for low-control structure, (for example, voltage scaling, 
exchanging improvement decay, compositional strategies for pipelining and parallelism, Computer-Aided Design (CAD) frameworks of gadget evaluating, interconnect, and premise progress) may not be agreeable in different applications, for example, favorable figuring contraptions, medicinal gear, where ultra-low-control use with medium rehash of activity (tens to a couple of $\mathrm{MHz}$ ) is the essential need. To conform to this, couple of novel game plan systems have been proposed. Essentialness recuperation or adiabatic procedures confirmations to diminish control in calculation by sales of importance. Regardless, it consolidates utilization of dumbfounding inductors which makes joining awkward. Significantly all the more beginning late, structure of bleeding edge subthreshold reason was examined with transistors worked in the subthreshold zone (supply voltage () not really the limit voltage ()) of the transistor). In such a methodology the subthreshold spillage current of the gadget is utilized for key estimation. This outcomes in high trans conductance addition of the contraptions (all things considered giving close impeccable voltage move characteristics of the premise passages) and reduced gateway input capacitance. Its effect on framework course of action is an exponential decrease of capacity to the burden of reduced execution. Computerized tally utilizing subthreshold spillage current has gotten a wide fervor for advancing quite a while to accomplish ultralow-control utilizes in adaptable enlisting contraptions.

\section{EXISTING SYSTEM}

To the degree current control float, by a long shot the greater part of structures right hand the uncommon straight control strategy, wherein the non-direct states of the STATCOM model are linearized with a specific concordance. The most widely used straight control plans are PI controllers. In administer responsive power, only an indisputable PI controller is hauled out. In a decoupled control procedure, the PI controller is used in a synchronous $\mathrm{d}-\mathrm{q}$ diagram. Everything thought of it as, is risky the suitable parameters for orchestrating the PI controller and the show of the PI controller may deteriorate with the outside annoying impact. Along these lines, unprecedented quick systems have been proposed, the PI controller advances like molecule swarm streamlining, neural structures, and counterfeit security. Recorded as a printed adaptation, flexible control and direct influencing clout have been addressed their enemy of outside irritating farthest point.

Recorded as a printed rendition, a phenomenal bum current controller is used. This control strategy has the high exchange speed and the spry recommendation current after pace. The enduring state achievement of H-interface fell STATCOM is invigorated, yet the dynamic execution isn't improved. In a dc mix end system called IDCF is proposed to collect an extra assessment drift for the dc bit of the yield current. It can improve the yield current nature of STATCOM. Regardless, the circuit structure of the fell STATCOM is the delta game-plan, regardless not the star system. Moreover, a versatile theory based improved tireless sinusoidal tracer control technique is proposed and a defective least mean square-based standard style is proposed.

Before long, these strategies are not for STATCOM with the fell structure. By using the standard straight control approach, the controller is delineated by its quick control structure and parameter plan comfort, yet poor persuading control quality.
Various checks increment to nonlinear power which clearly compensates for the structure nonlinearities without requiring a speedy theory. In a data yield assessment linearization controller is arranged. By perceiving a damping term, the affecting abundancy of inside parts can be reasonably decreased. In any case, the security can't be guaranteed. By then, unique new changed damping controllers are required to prop the controllability and execution of inside fragments.

\section{PROPOSED SYSTEM}

The Hybrid Renewable Energy System showed up in Figure contains a $200 \mathrm{~kW}$ wind turbine MICON M450-200 which has a nonconcurrent machine working at $400 \mathrm{~V}$ whose subtleties can be seen at [20]. A $75 \mathrm{~kW}$ PV board is associated with the HRES through a rectifier to pass on trading current. It is run of the mill that the proposed windPV structure goes about as a power imbuement system to the power structure and misses the mark on the features to apply any kind of intensity quality control on the power made. The power made by the breeze turbine is genuinely planned by systems for AC cross portion to the scattering station. The power from the sun controlled sheets is continued to the framework by procedures for DC-AC converter. A bidirectional charge controller charges/discharges the battery and manages the AC-DC change and voltage boosting. The impossible to miss thought of inconceivable sources makes the structure unequipped for get-together the power dispatch checks of the stack dispatch centers. Moreover, now and then of high wind openness the turbines are constrained to shut down due to nonattendance of power clearing workplaces.

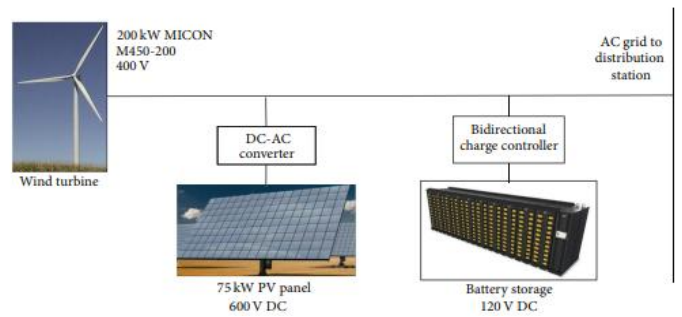

Figure Schematic diagram of Hybrid Renewable Energy System.

Dealing with battery with the HRES will store the spilled centrality and pass on it from time to time of apex power demands as such improving the structure suffering quality. The system used for assessing and evaluation is showed up in Figure. From the start, control passed on by the HRES is coordinated by exhibiting the structure parts. A quick power dispatch system is diagramed to clear all discontinuities in the made power.

It in like manner engages storing of essentialness at low intrigue periods and taking a break to time of apex load, that is, top shaving and slope rate restricting to keep away from unexpected floods entering the cross region.

\section{APPLICATIONS}

- Graphic on, which contains 26 VLSI chips of 11 plan sorts including two custom ones, can exhibit 3D pictures at the pace of 10,000 triangles for reliably.

- Ultrasound managing will most likely be influenced by VLSI headway more than some

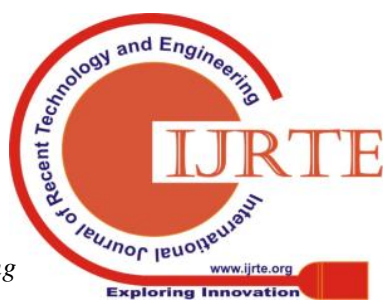


other supportive imaging process, as VLSI is used to execute completely mechanized front-terminations to advancing ultrasound composed gathering signal processor.

- The happening to silicon compiler CAD contraptions will in like way empower the fast course of action of custom VLSI picture preparing ICs.

\section{VIII.METHODOLOGY}

\section{Ultra capacitor Voltage Control}

The control of the battery converter input current reference (i $\square \square \square \square \square$ ) is done reliant on the ultra capacitor voltage $\square \square \square$. For this, the boundless oversight diagram of the system presented in Fig. is used. Presently, simply the stack current (i $\square$ ) is managed an inconvenience and each and every other variable become some part of the model.

$$
\frac{V_{u c}}{I_{i-b t}^{*}}=\frac{V_{b t}}{V_{o} C_{0} C_{u c}} \frac{H_{i-b t} G_{c-v o} H_{i-u c}\left(1+s C_{u c} R_{u c}\right)}{s\left(s+\frac{G_{c-v o} H_{i-u c} V_{u c}}{C_{o} V_{o}}\right)}
$$

This trade limit allows the amalgamation of a controller for accountable for restoring the ultracapacitor voltage to the compelled to a repeat much lower than the yield voltage demand. Basically after the ultracapacitor voltage is bothered, voltage to the reference level $(\square \square \square \square$ ). controllers achieves an expulsion of force best by the battery. As the control action restores ultracapacitor voltage, ultracapacitor works in a charge-supporting mode, that is, it will in general be charged or discharged until its places of imprisonment, anyway after vagrants its voltage will be reclaimed to the reference level $(\square \square \square)$.

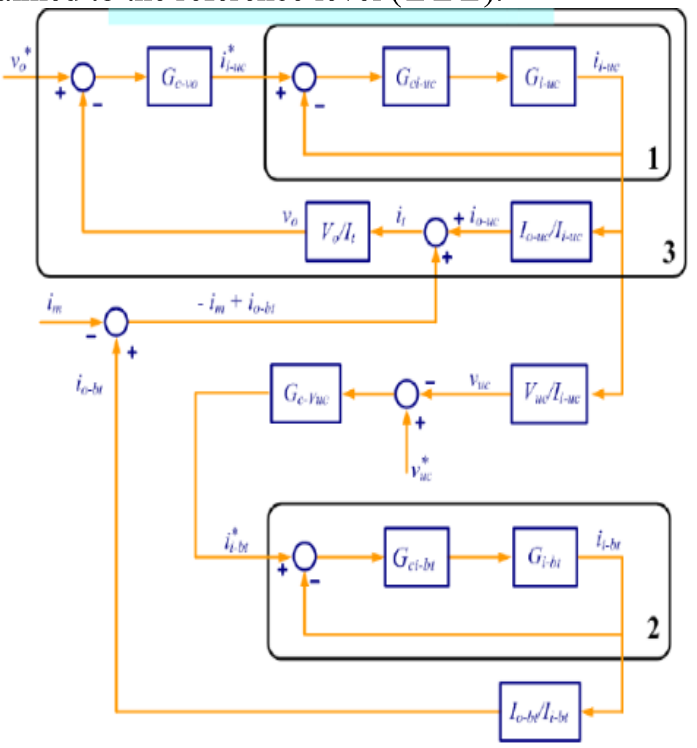

Figure Control diagram

\section{RESULTS}

Figure shows the exploratory set-up. The control estimation is executed in an Analog Devices 16-bit DSP (ADSP-21992). ultracapacitor voltage ( $\square \square \square \square \square \square$ ). This controller is reference level $(\square \square \square \square)$. Its information move limit is controller ( $\quad \square \square \square \square \square$ ), hence the ultracapacitor is the essential contraption to be affected by a change in weight battery current will be adjusted to restore ultracapacitor

This refinement in the transmission limit of the voltage

The DSP and sign embellishment sheets are in position A The gear (B) used to comprehend the converter is a Semikron four-leg (each leg made by a SKM50GB123D IGBT module) inverter interface module. One leg is used for battery converter, another for ultracapacitor converter, another for overvoltage request and the other one isn't used. Inductors are encased in a metal box (C), for lessening of EMI. A resistive weight (D) is used to reproduce the stack. Twelve methodology related lead-hazardous batteries, reviewed $12 \mathrm{~V}$, $2.2 \mathrm{Ah}$ each, totaling $144 \mathrm{~V}, 2.2 \mathrm{Ah}$ and five plan related ultracapacitors modules made by Maxwell Technologies, surveyed $42 \mathrm{~V}, 150 \mathrm{~F}$ each, totaling $210 \mathrm{~V}, 30 \mathrm{~F}$ were used $(\mathrm{E})$.

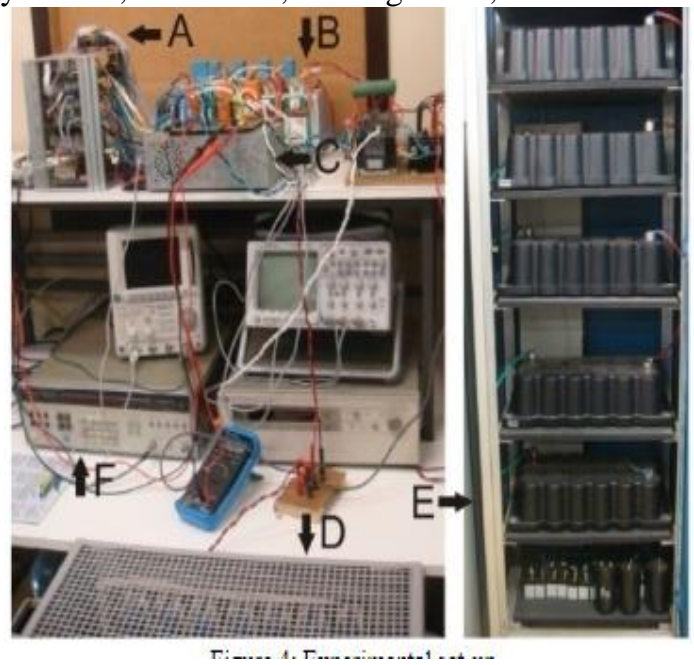

Figure Experimental set-up

For the showing up of converters, state space averaging method was used, which contains recorded as a printed copy the state space states of the circuit for each possible game-plan of the switches, than basic the cross fragments of the system thought about when spent in each state. The showing up of these converters displays a non-least stage structure (that is, with a zero on the right-half plane).

Current mode control decreases this trademark, in light of the way in which that the yield circle has a more minor information move limit than the current-control circle, and the deals for the structure is diminished. The two current controllers (with information move most remote purpose of 1 $\mathrm{kHz}$ ) and the yield voltage controller (with transmission most extreme of $100 \mathrm{~Hz}$ ) were planned using the k-factor structure.

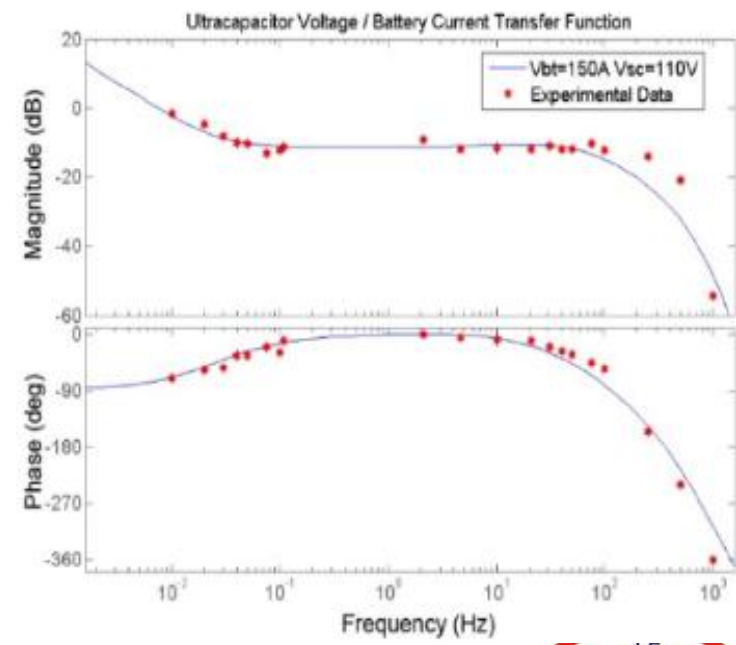

Figure Model validation with experimental data 
By and by essentially this three of the four controllers appeared in Fig. 3 are dynamic on the DSP. To attest the change of the model, the exchange furthest reaches of (2) was likely assessed. This estimation was created utilizing a sign generator (F) to convey a sinusoid gotten by the DSP and utilized as battery current reference. In this examination, all controllers are dynamic, close to Magnitude and time of reference and of coming about disturbing in ultracapacitor voltage were evaluated utilizing an oscilloscope. The test result is showed up contrastingly in connection to exhibit want in Fig.

\section{CONCLUSION}

The battery-ultra capacitor hybridization can pass on fundamental focal points to electric vehicles, because of the high top to-average power sales of this application and the indispensable qualities of batteries and ultra capacitors. Another control method to mastermind the power stream was introduced. The methodology can be acknowledged with low computational expense. Basically, the proposed control procedure arranges the yield voltage and reestablishes ultra-capacitor voltage after vagrants. It withdraws the power request into low-rehash parts and high-rehash divides. The low-rehash parts are given by the battery, while high-rehash segments are given by the ultra capacitor.

The total of the power given by the two sources at every depiction of time is fundamentally indistinguishable from the power request, as basic to keep the yield voltage stable. As the framework goes about as a low pass channel for the battery current, the RMS current on battery is diminished (regarding a structure with battery just), and higher sufficiency on utmost is ordinary. Likewise, lower release rates and incapacitating of high recurrent parts in battery current should acknowledge longer battery life.

\section{FUTURE SCOPE}

During this assessment, we orchestrated and delivered another model single cell. Cell course of action is given. A short stack containing five cells was besides fabricated. Both the single cell and short stack will be endeavored and reexamined soon.

\section{REFERENCES}

[1] "Battery power for your residential solar electric system," Technical Report, National Renewable Energy Laboratory, 2002.

[2] "Electrical energy storage," Technical Report, International Electrochemical Commission http://www.iec.ch/whitepaper/pdf/iecWP-energystorageLR-en.pdf, 2011.

[3] P. R. Abel, Y.-M. Lin, H. Celio, A. Heller, and C. B. Mullins, "Improving the stability of nanostructured silicon thin film lithium-ion battery anodes through their controlled oxidation," ACS Nano, vol. 6, no. 3, pp. 2506-2516, 2012.

[4] P. R. Abel, Y.-M. Lin, H. Celio, A. Heller, and C. B. Mullins, "Improving the stability of nanostructured silicon thin film lithium-ion battery anodes through their controlled oxidation," ACS Nano, vol. 6, no. 3, pp. 2506-2516, 2012.

[5] H. Akagi and H. Sato, "Control and performance of a doubly-fed induction machine intended for a flywheel energy storage system," IEEE Transactions on Power Electronics, vol. 17, no. 1, pp. 109-116, 2002.

[6] A. Allegre, A. Bouscayrol, and R. Trigui, "Influence of control strategies on battery/supercapacitor hybrid energy storage systems for traction

applications," in Proceedings of the Vehicle Power and Propulsion Conference (VPPC), pp. 213-220, 2009.

[7] F. Altaf, L. Johannesson, and B. Egardt, "Performance evaluation of multilevel converter based cell balancer with reciprocating air flow," in Proceedings of the Vehicle Power and Propulsion Conference (VPPC), pp. 706-713, 2012

[8] S. M. Amin and B. F. Wollenberg, "Toward a smart grid: power delivery for the 21st century," IEEE Power and Energy Magazine, vol. 3, no. 5, pp. 34-41, 2005

[9] T. B. Atwater, P. J. Cygan, and F. C. Leung, "Man portable power needs of the 21st century: I. applications for the dismounted soldier. ii. enhanced capabilities through the use of hybrid power sources," Journal of Power Sources, vol. 91, no. 1, pp. 27-36, 2000.

[10] L. Barote, R. Weissbach, R. Teodorescu, C. Marinescu, and M. Cirstea, "Stand-alone wind system with vanadium redox battery energy storage," in Proceedings of the International Conference on Optimization of Electrical and Electronic Equipment (OPTIM), pp. 407-412, 2008.

[11] Y. Barsukov, "Battery cell balancing: What to balance and how," Technical Report, Texas Instruments, 2009.

[12] S. Bashash, S. J. Moura, J. C. Forman, and H. K. Fathy, "Plug-in hybrid electric vehicle charge pattern optimization for energy cost and battery longevity," Journal of Power Sources, vol. 196, no. 1, pp. 541-549, 2011.

[13] F. Belhachemi, S. Ra“el, and B. Davat, "A physical based model of power electric double-layer supercapacitors," in Proceedings of the Industry Applications Conference, vol. 5, pp. 3069-3076, 2000

[14] J. L. Bernal-Agustn and R. Dufo-L'opez, "Simulation and optimization of stand-alone hybrid renewable energy systems," Renewable and Sustainable Energy Reviews, vol. 13, no. 8, pp. 2111-2118, 2009.

[15] P. Bhatnagar and R. Nema, "Maximum power point tracking control techniques: State-of-the-art in photovoltaic applications," Renewable and Sustainable Energy Reviews, vol. 23, pp. 224-241, 2013.

[16] A. Bilodeau and K. Agbossou, "Control analysis of renewable energy system with hydrogen storage for residential applications," Journal of Power Sources, vol. 162, no. 2, pp. 757-764, 2006.

[17] S. Boyd and L. Vandenberghe, Convex Optimization. Cambridge University Press, 2004

[18] D. Bresser, E. Paillard, M. Copley, P. Bishop, M. Winter, and S. Passerini, "The importance of "going nano" for high power battery materials," Journal of Power Sources, vol. 219, pp. 217-222, 2012.

[19] D. A. Brownson, D. K. Kampouris, and C. E. Banks, "An overview of graphene in energy production and storage applications," Journal of Power Sources, vol. 196, no. 11, pp. 4873-4885, 2011.

[20] S. Brutti, J. Hassoun, B. Scrosati, C.-Y. Lin, H. Wu, and H.-W. Hsieh, "A high power Sn-C/C-LiFePO4 lithium ion battery," Journal of Power Sources, vol. 217, pp. 72-76, 2012.

[21] S. Buller, E. Karden, D. Kok, and R. De Doncker, "Modeling the dynamic behavior of supercapacitors using impedance spectroscopy," in Proceedings of the Industry Applications Conference, vol. 4, pp. 2500-2504, 2001.

[22] S. Buller, M. Thele, R. De Doncker, and E. Karden, "Impedance-based simulation models of supercapacitors and li-ion batteries for power electronic applications," IEEE Transactions on Industry Applications, vol. 41, no. 3, pp. 742-747, 2005.

[23] S. Caron and G. Kesidis, "Incentive-based energy consumption scheduling algorithms for the smart grid," in Proceedings of the Smart Grid Communications (SmartGridComm) Conference, pp. 391-396, 2010.

[24] P. Carter, J. Baxter, T. Newill, and T. Erekson, "An ultracapacitor-powered race car update," in Proceeding of the Electrical Insulation Conference and Electrical Manufacturing Expo, pp. 267-274, 2005.

[25] S. Chakraborty, M. Lukasiewycz, C. Buckl, S. Fahmy, N. Chang, S. Park, Y. Kim, P. Leteinturier, and H. Adlkofer, "Embedded systems and software challenges in electric vehicles," in Proceedings of the Design, Automation and Test in Europe Conference and Exhibition (DATE), pp. 424-429, 2012.

[26] N. Chang and M. Pedram, "Hybrid electrical energy storage systems," Tutorial at International Symposium on 
Quality Electronics Design (ISQED), 2011.

[27] N. Chang, J. Seo, D. Shin, and Y. Kim, "Room-temperature fuel cells and their integration into portable and embedded systems," in Proceedings of the Asia and South Pacific Design Automation Conference (ASP-DAC), pp. 69-74, 2010.

[28] P. Chanhom, S. Sirisukprasert, and N. Hatti, "DC-link voltage optimization for SOC balancing control of a battery energy storage system based on a 7-level cascaded PWM converter," in Proceedings of the International Conference on Electrical Engineering/Electronics, Computer, Telecommunications and Information Technology (ECTI-CON), pp. 1-4, 2012.

[29] C. Chen, B. Das, and D. J. Cook, "Energy prediction based on resident's activity," in Proceedings of the International Workshop on Knowledge Discovery from Sensor Data (SensorKDD), 2010.

[30] C.-Y. Chen and P. H. Chou, "DuraCap: a supercapacitor-based, powerbootstrapping, maximum power point tracking energy-harvesting system," in Proceedings of the International Symposium on Low-Power Electronics and Design (ISLPED), pp. 313-318, 2010.

[31] H. Chen, T. N. Cong, W. Yang, C. Tan, Y. Li, and Y. Ding, "Progress in electrical energy storage system: A critical review," Progress in Natural Science, vol. 19, no. 3, pp. 291-312, 2009.

[32] Q. Cheng, J. Tang, J. Ma, H. Zhang, N. Shinya, and L.-C. Qin, "Graphene and carbon nanotube composite electrodes for supercapacitors with ultrahigh energy density," Physical Chemistry Chemical Physics, vol. 13, no. 39, pp. 17615-17624, 2011.

[33] Q. Cheng, J. Tang, J. Ma, H. Zhang, N. Shinya, and L.-C. Qin, "Graphene and nanostructured $\mathrm{MnO} 2$ composite electrodes for supercapacitors," Carbon, vol. 49, no. 9, pp. 2917-2925, 2011.

[34] Y. Cheng, V. Joeri, and P. Lataire, "Research and test platform for hybrid electric vehicle with the super capacitor based energy storage," in Proceedings of the European Conference on Power Electronics and Applications, pp. 1-10, 2007.

[35] S. Chiang, K. Chang, and C. Yen, "Residential photovoltaic energy storage system," IEEE Transactions on Industrial Electronics, vol. 45, no. 3, pp. 358-394, 1998.

[36] Y. Choi, N. Chang, and T. Kim, "DC-DC converter-aware power management for low-power embedded systems," IEEE Transactions on Computer-Aided Design of Integrated Circuits and Systems, vol. 26, no. 8, pp. 1367-1381, 2007.

[37] M. Chowdhury, M. Haque, M. Aktarujjaman, M. Negnevitsky, and A Gargoom, "Grid integration impacts and energy storage systems for wind energy applications - a review," in Proceedings of the Power and Energy Society General Meeting, pp. 1-8, 2011.

[38] Consolidated Edison Company of New York, Inc. 2012, "Service classification no. 1 - residential and religious,"

[39] A. Czerwi'nski, S. Obrbowski, and Z. Rogulski, "New high-energy lead-acid battery with reticulated vitreous carbon as a carrier and current collector," Journal of Power Sources, vol. 198, pp. 378-382, 2012.

[40] K. Darcovich, N. Gupta, I. Davidson, and T. Caroni, "Residential electrical power storage scenario simulations with a large-scale lithium ion battery," Journal of Applied Electrochemistry, vol. 40, pp. 749-755, 2010.

[41] J. P. Deane, B. P. O. Gallach' ' oir, and E. McKeogh, "Techno-economic review of existing and new pumped hydro energy storage plant," Renewable and Sustainable Energy Reviews, vol. 14, no. 4, pp. 1293-1302, 2010.

[42] K. Divya and J. Østergaard, "Battery energy storage technology for power systems - an overview," Electric Power Systems Research, vol. 79, no. 4, pp. 511-520, 2009.

[43] D. Doerffel and S. A. Sharkh, "A critical review of using the peukert equation for determining the remaining capacity of lead-acid and lithium-ion batteries," Journal of Power Sources, vol. 155, no. 2, pp. 395-400, 2006.

[44] R. Dougal, S. Liu, and R. White, "Power and life extension of batteryultracapacitor hybrids," IEEE Transactions on Components and Packaging Technologies, vol. 25, no. 1, pp. 120-131, 2002.

[45] M. Einhorn, W. Roessler, and J. Fleig, "Improved performance of serially connected li-ion batteries with active cell balancing in electric vehicles," IEEE Transactions on Vehicular Technology, vol. 60, no. 6, pp. 2448-2457, 2011.

[46] O. Ekren and B. Y. Ekren, "Size optimization of a PV/wind hybrid energy conversion system with battery storage using simulated annealing," Applied Energy, vol. 87, no. 2, pp. 592-598, 2010.

[47] O. Ekren, B. Y. Ekren, and B. Ozerdem, "Break-even analysis and size optimization of a PV/wind hybrid energy conversion system with battery storage — a case study," Applied Energy, vol. 86, no. 78, pp 1043-1054, 2009.

[48] T. Esram and P. Chapman, "Comparison of photovoltaic array maximum power point tracking techniques," IEEE Transactions on Energy Conversion, vol. 22, no. 2, pp. 439-449, 2007.

[49] A. Evans, V. Strezov, and T. J. Evans, "Assessment of utility energy storage options for increased renewable energy penetration," Renewable and Sustainable Energy Reviews, vol. 16, no. 6, pp. 4141-4147, 2012.

[50] C. Fabjan, J. Garche, B. Harrer, L. Jrissen, C. Kolbeck, F. Philippi, G. Tomazic, and F. Wagner, "The vanadium redox-battery: An efficient storage unit for photovoltaic systems," Electrochimica Acta, vol. 47, no. 5, pp. 825-831, 2001. 